\title{
Studying physico-mechanical properties of maleic acid grafted chitosan with metal as slow release fertilizers
}

\author{
El-Sayed Negim ${ }^{1 *}$, Lyazzat Bekbayeva ${ }^{2}$, Laura Jumabayeva ${ }^{3}$, Azhar Bakyt ${ }^{3}$, Aigul Imandossova ${ }^{3}$, Assel \\ Zhanybekova $^{3}$, Shynar Yegizbayeva ${ }^{3}$, Zhanerke Karimzhanova ${ }^{3}$, Datkhayev Ubaidilla ${ }^{3}$, Misni Surif ${ }^{4}$ \\ ${ }^{1}$ Faculty of Science and Engineering, University of Wolverhampton, Wulfruna Street, Wolverhampton, WV1 1LY, UK \\ ${ }^{2}$ School of Distance Education, Universiti Sains Malaysia, 11800 Penang, Malaysia \\ ${ }^{3}$ Asfendiyarov Kazakh National Medical University, Pharmaceutical Faculty, Almaty, Kazakhstan \\ ${ }^{4}$ Centre for Marine and Coastal Study, Universiti Sains Malaysia, 11800 Penang, Malaysia \\ *Corresponding author E-mail: elashmawi5@yahoo.com
}

Copyright $\odot 2015$ El-Sayed Negimet al. This is an open access article distributed under the Creative Commons Attribution License, which permits unrestricted use, distribution, and reproduction in any medium, provided the original work is properly cited.

\begin{abstract}
Chitosan (CS) was successfully grafted with maleic acid (MA) in $1 \%$ acetic acid solution by using potassium persulfate (KPS) as the initiator. The grafting yield (GY) up to $84.25 \%$ and grafting efficiency (GE) of $64.82 \%$ were achieved. The formation of grafted chitosan was confirmed with usual spectroscopic methods and thermal analysis. The raw grafted chitosan was mixed with $\mathrm{Na}^{+}, \mathrm{Mg}^{2+}$ and $\mathrm{Ca}^{2+}$ in aqueous hydroxide solution and $\mathrm{K}^{+}$in aqueous chromate solution. The reaction mixtures were separated from excess unreacted maleic acid and characterized as a reacted grafted chitosan. The results showed a new form of maleic grafted chitosan after the reaction with metals. Also, grafted of CS with MA provide a promising set of materials for potential slow release fertilizer applications.
\end{abstract}

Keywords: Grafting; Chitosan; Maleic Acid; Potassium Persulfate; Metal Ions.

\section{Introduction}

Chitosan, poly [ $\beta$-(1-4)-2-amino-2-deoxy- D-glucose], is the N-deacetylated form of chitin and has many useful features such as hydrophilicity, biocompatibility, biodegradability, antibacterial property, ion-chelating ability, and a remarkable affinity for many proteins and fats [1]. The deacetylated product, chitosan, has an amine functional group, which is strongly reactive with metal ions. The deacetylation degree will control the content of glucosamine and therefore the fraction of free amine groups available for metal binding. These groups are more reactive than the acetamide groups present on chitin. Also their solubility in acidic solutions differs, chitosan being soluble. The physicochemical properties of chitosan depend on various parameters such as degree of deacetylation and polymer weight [2]. Many researchers are now looking at the ability of this amino group to adsorb metal ions from industrial wastewater and leachates. The presence of heavy metal in environment is of major concern because of their transformation from relatively low toxic species into more toxic ones [3]. This review presents the developments in this area and identifies the defficiences in existing chitosan research by reviewing the equilibrium studies carried out to determine the capacity of chitosan for various metal ions [4]. To improve chitosan's performance as an adsorbent, crosslinking reagents such as glyoxal, formaldehyde, glutaraldehyde, epichlorohydrin, ethylene glycon, diglycidyl ether and isocyanates have been used [5]. Crosslinking agents do not only stabilize chitosan in acid solutions so that it becomes insoluble but also enhance its mechanical properties [6]. So the stability may be attained by chemical modifications. Chemical modifications that lead to the formation of chitosan derivatives, grafting chitosan and chitosan composites have gained much attention, extensively studied and widely reported in the literatures. Grafting of vinyl monomers onto chitosan is one way of achieving chemical modification of this amino polysaccharide. Several studies concerning graft copolymerization on chitin or chitosan have been reported. Redox initiators like Fenton's reagent, potassium persulfate, and cerium (IV) ammonium nitrate (CAN) have been found to be effective for this purpose [5-6]. Although maleic acid 
is not an ordinary vinyl monomer, it has been reported to polymerize in water in the presence of potassium persulfate and poly (N-vinyl pyrrolidinone) [7].

The graft copolymer is an effective superabsorbent resin (SAR) and can absorb water 704 times its own dry weight [8]. Chitosan is easier to work with than chitin due to the protonation of amine groups in dilute acid solutions, especially acetic acid, leading to solubility [1].

In the present study, we report the grafting of chitosan with maleic acid in the presence of potassium persulfate as an initiator. Then, the grafted chitosan react with metal ions and all the samples were confirmed with usual spectroscopic methods and thermal analysis.

\section{Experimental}

\subsection{Materials and apparatus}

Chitosan, maleic acid and potassium persulfate were supplied from Aldrich. Acetic acid, 2-propanol and all other chemicals used in the experiments were obtained from Changchun Jincheng Corn Development Co. Ltd., Da Cheng Group (China).

\subsection{Grafting of chitosan}

The grafted polymerization was prepared as previously described in the literature [9-11] and as the following: Chitosan (5.0g,) dissolved in $1 \%$ acetic acid solution $(200 \mathrm{~g})$, by stirring, in the water bath at $70^{\circ} \mathrm{C}$. After soluble, a known amount of potassium persulfate $(0.2 \mathrm{~g}, 0.74 \mathrm{mmol}$ in $10 \mathrm{ml}$ of distilled water) was added as an initiator. After $5 \mathrm{mins}$., a solution of maleic acid $(20 \mathrm{~g}, 172.31 \mathrm{mmol}$ in $50 \mathrm{ml}$ of distilled water) was added by dropping for 30 mins. The mixture was left for 3 hours at $70^{\circ} \mathrm{C}$ in nitrogen atmosphere under continuous stirring. 2-propanol was used to precipitate the product. The product was dried at room temperature. The homopolymer of maleic acid was removed from the graft copolymer by exhaustive Soxhlet extraction with acetone for $36 \mathrm{~h}$. The final copolymer was then dried to a constant weight in an oven at $60^{\circ} \mathrm{C}$. The grafting yield (GY \%) and grafting efficiency (GE \%) was calculated as follows [12] :

Grafting Efficiency $(\mathrm{GE} \%)=\frac{W g}{W g+W i} \times 100$

Grafting Yield $(\mathrm{GY} \%)=\frac{W g-W i}{W i} \times 100$

Where, $\mathrm{Wg}=$ Weight of grafted copolymer

$\mathrm{Wi}=$ Weight of homopolymer

\subsection{Reaction of metal with raw grafted chitosan}

An unknown mass of CS-g-MA was mixed with $\mathrm{Na}^{+}, \mathrm{Mg}^{2+}$ and $\mathrm{Ca}^{2+}$ in aqueous hydroxide solution and $\mathrm{K}^{+}$in aqueous chromate solution. The reaction was continued until obtained the $\mathrm{pH} 7$ for every reaction. 2-propanol was used to precipitate the product. The product was then dried at room temperature.

\subsection{Tests}

FT-IR data were recorded on a Perkin Elmer 2000-FTIR spectrophotometer in frequency range of $4000-400 \mathrm{~cm}^{-1}$ and in solid state with samples embedded in $\mathrm{KBr}$ discs. DSC was carried out using a Perkin Elmer Differential Scanning Calorimeter DSC. The samples were tested under $\mathrm{N}_{2}$ atmosphere at a scanning rate $\pm 20{ }^{\circ} \mathrm{Cmin}^{-1}$. The thermal gravimetric analysis (TGA) was conducted on a TGA/SDTA $851 \mathrm{e}$ under nitrogen flow. The heating rate was $20^{\circ} \mathrm{C} / \mathrm{min}$. For SEM, the samples were gold sputtered and observed at an accelerating voltage of $10 \mathrm{kV}$, in order to avoid membrane degradation. For EDX analysis, samples were carbon sputtered and the correspondent cross-sections were analyzed at an accelerating voltage of $10 \mathrm{kV}$. EDX quantification of metal/carbon/oxygen/nitrogen intensity ratio was normalized to $100 \%$ at the surface, for each sample.

\section{Results and discussion}

\subsection{Grafting efficiency (GE) and grafting yield (GY)}

Based on the calculations, the grafting yield (GY) up to $84.25 \%$ and grafting efficiency (GE) of $64.82 \%$ were achieved. According to this, chitosan was successfully grafted to maleic acid. 


\subsection{FT-IR spectra}

The IR spectra of the chitosan and the grafted chitosan with maleic acid are shown in Fig. 1. Fig. 1a showed that the main characteristic peaks of chitosan are at $3432 \mathrm{~cm}^{-1}(\mathrm{O}-\mathrm{H}$ stretch $), 2887 \mathrm{~cm}^{-1}$ (C-H stretch), $1637 \mathrm{~cm}^{-1}(\mathrm{~N}-\mathrm{H} \mathrm{bend})$, $1384 \mathrm{~cm}^{-1}$ (C-N stretch) and $1161 \mathrm{~cm}^{-1}$ (asymmetric stretching of the $\mathrm{C}-\mathrm{O}-\mathrm{C}$ bridge)[13].

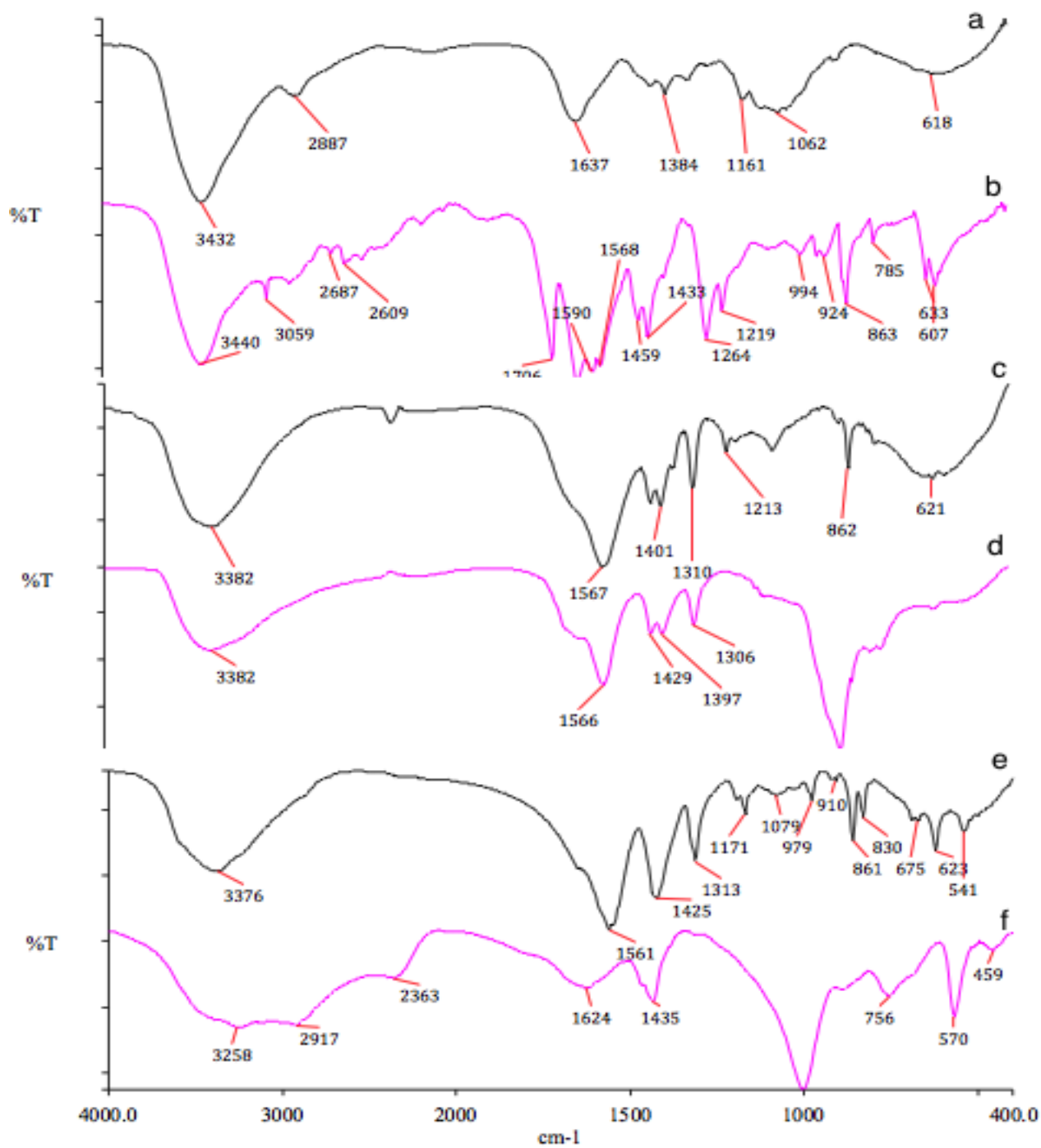

Fig. 1: FT-IR Spectrum of (A) Chitosan, (B) CS-G-MA, (C) $\mathrm{Na}^{+}$, (D) with $\mathrm{K}^{+}$, (E) $\mathrm{Ca}^{2+}$, and (F) $\mathrm{Mg}^{2+}$

For the spectrum of grafted chitosan, in Fig.1b, some new absorption peaks appeared. The peak at $1706 \mathrm{~cm}^{-1}$ corresponds to the $\mathrm{C}=\mathrm{O}$ vibrations of maleic acid introduced onto the chitosan [1]. The peaks at $1219 \mathrm{~cm}^{-1}$ and $1264 \mathrm{~cm}^{-}$ ${ }^{1}$ corresponded to the $\mathrm{C}-\mathrm{O}$ stretch of the acid. At $3059 \mathrm{~cm}^{-1}, 2687 \mathrm{~cm}^{-1}$ and $2609 \mathrm{~cm}^{-1}$ attributed to OH stretch of the acid. The peaks at $1459 \mathrm{~cm}^{-1}$ and $1433 \mathrm{~cm}^{-1}$ indicated the $\mathrm{OH}$ bend of the acid. For the spectrums of grafted chitosan react with metals, Fig. 1c-d and Fig. 1e-f shown that the peak of carbonyl group are shifted from $1706 \mathrm{~cm}^{-1}$ to 1510 $1650 \mathrm{~cm}^{-1}$. Fig. 1c, band at $1567 \mathrm{~cm}^{-1}$ corresponds to the sodium carboxylate group. For Fig. $1 \mathrm{~d}$, band at $1566 \mathrm{~cm}^{-1}$ corresponds to the K carboxylate group. At Fig. 1e, band at $1561 \mathrm{~cm}^{-1}$ correspond to Ca carboxylate group. For Fig. $1 \mathrm{f}$ bands at $1624 \mathrm{~cm}^{-1}$ correspond to the $\mathrm{Mg}$ carboxylate group. The results revealed that grafted chitosan was reacting with metal [14].

\subsection{Differential scanning calorimetry (DSC)}

DSC curves of CS, CS - g- MA and CS- g- MA-Metals are shown in Figures 2 and 3. All the DSC curves showed the single $T_{g}$ value, which confirmed the miscibility of grafting maleic acid with chitosan. From the data in Table $1, T_{g}$ value of chitosan, which was $92.92{ }^{\circ} \mathrm{C}$, increased to $135.00{ }^{\circ} \mathrm{C}$ after grafted with maleic acid. Then the values decreased to $124.00{ }^{\circ} \mathrm{C}, 120.00{ }^{\circ} \mathrm{C}, 79.13{ }^{\circ} \mathrm{C}$ and $94.58{ }^{\circ} \mathrm{C}$ after grafted chitosan react with $\mathrm{Na}^{+}, \mathrm{Mg}^{2+}, \mathrm{Ca}^{2+}$ and $\mathrm{K}^{+}$. Tm value of chitosan increased after grafted with maleic acid from $118.00{ }^{\circ} \mathrm{C}$ to $164.94{ }^{\circ} \mathrm{C}$. 
Table 1: Thermal Properties of CS-G-MA and (CS-G-MA) M Films.

\begin{tabular}{|c|c|c|c|c|c|c|c|}
\hline Polymer & $\begin{array}{l}\text { Step } \\
\text { Stage }\end{array}$ & $\begin{array}{l}\text { Temperature } \\
\text { Range }\left({ }^{\circ} \mathrm{C}\right)\end{array}$ & $\begin{array}{l}\text { Weight } \\
\text { Loss \% }\end{array}$ & $\begin{array}{l}\text { Residue } \\
\%\end{array}$ & $\begin{array}{l}\text { IDT }^{b} \\
{ }^{\circ} \mathrm{C}\end{array}$ & $\begin{array}{l}T_{g}^{\mathrm{a}} \\
{ }^{\mathrm{o}} \mathrm{C}\end{array}$ & $\begin{array}{c}T_{m}{ }^{\mathrm{a}} \\
{ }^{\circ} \mathrm{C}\end{array}$ \\
\hline CHITOSAN & $\begin{array}{l}1 \\
2\end{array}$ & $\begin{array}{l}29.38-202.36 \\
202.36-897.27\end{array}$ & $\begin{array}{l}12.69 \\
55.57\end{array}$ & $\begin{array}{l}87.29 \\
31.73\end{array}$ & 310 & 92.92 & 118.00 \\
\hline CS-g-MA & $\begin{array}{l}1 \\
2 \\
3\end{array}$ & $\begin{array}{l}29.80-161.91 \\
161.91-300.90 \\
300.90-895.47\end{array}$ & $\begin{array}{l}21.65 \\
40.95 \\
16.49 \\
\end{array}$ & $\begin{array}{l}78.33 \\
37.37 \\
20.89 \\
\end{array}$ & 180 & 135.0 & 164.94 \\
\hline CS-g-MA-Na & $\begin{array}{l}1 \\
2\end{array}$ & $\begin{array}{l}29.42-143.56 \\
143.56-900.33\end{array}$ & $\begin{array}{l}18.26 \\
38.81\end{array}$ & $\begin{array}{l}82.20 \\
43.39\end{array}$ & 80 & 124.0 & 127.41 \\
\hline CS-g-MA-Mg & $\begin{array}{l}1 \\
2\end{array}$ & $\begin{array}{l}29.94-257.51 \\
257.51-900.62\end{array}$ & $\begin{array}{l}42.83 \\
8.19\end{array}$ & $\begin{array}{l}57.19 \\
49.00\end{array}$ & 122 & 120.0 & 127.84 \\
\hline CS-g-MA-Ca & $\begin{array}{l}1 \\
2 \\
3\end{array}$ & $\begin{array}{l}29.78-104.71 \\
104.71-247.26 \\
247.26-900.91 \\
\end{array}$ & $\begin{array}{l}4.14 \\
14.24 \\
20.39 \\
\end{array}$ & $\begin{array}{l}96.04 \\
81.81 \\
61.41 \\
\end{array}$ & 180 & 79.13 & 187.26 \\
\hline CS-g-MA-K & $\begin{array}{l}1 \\
2 \\
3 \\
4 \\
5\end{array}$ & $\begin{array}{l}29.54-195.70 \\
195.70-347.24 \\
347.24-557.98 \\
557.98-688.45 \\
688.45-899.84\end{array}$ & $\begin{array}{l}13.45 \\
4.58 \\
8.37 \\
2.28 \\
7.91\end{array}$ & $\begin{array}{l}86.93 \\
82.35 \\
73.99 \\
71.71 \\
63.80\end{array}$ & 74 & 94.58 & 487.51 \\
\hline
\end{tabular}

a) Determined from DSC curves.

b) Determined from TGA curves.

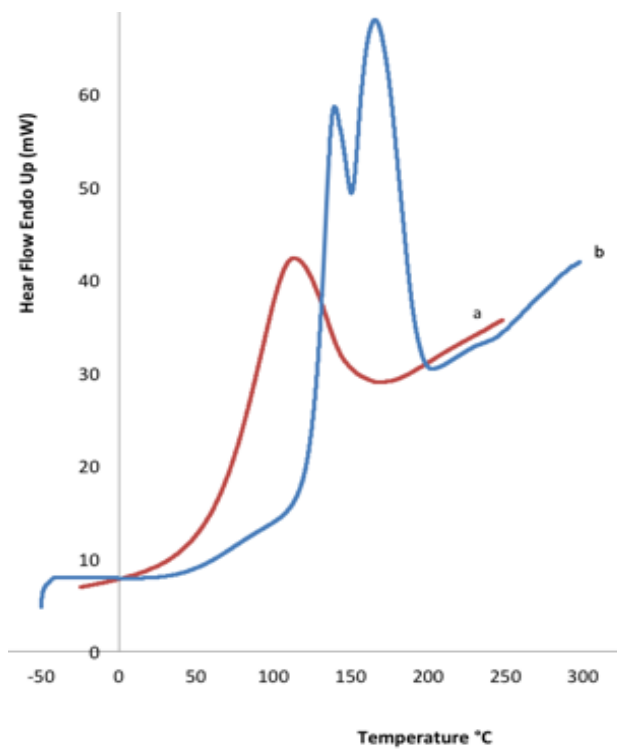

Fig. 2: DSC of CS (A) and CS-G-MA (B)

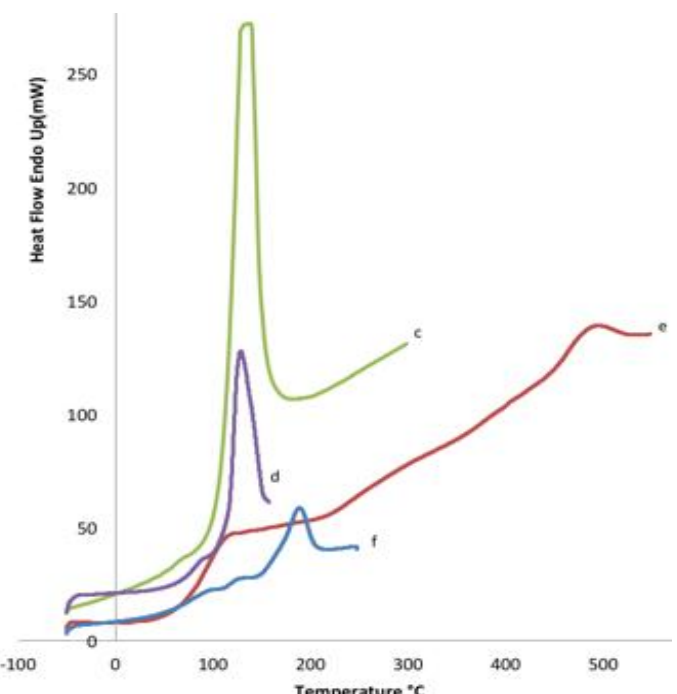

Fig. 3: DSC of CS-G-MA Reacts with $\mathrm{Mg}^{2+}(\mathrm{C}), \mathrm{Na}^{+}(\mathrm{D}), \mathrm{K}^{+}(\mathrm{E})$ and $\mathrm{Ca}^{2+}(\mathrm{F})$ 
The value of Tm for grafted chitosan react with $\mathrm{Na}^{+}$and $\mathrm{Mg}^{2+}$ decreased to $127.41{ }^{\circ} \mathrm{C}$ and $127.84{ }^{\circ} \mathrm{C}$. For reaction with $\mathrm{Ca}^{2+}$ and $\mathrm{K}^{+}$, the value of $\mathrm{Tm}$ increased to $187.26{ }^{\circ} \mathrm{C}$ and $487.51{ }^{\circ} \mathrm{C}$. All these value showed that the reactions were successfully occurred.

\subsection{Thermo gravimetric analysis (TGA)}

The thermal stability and degradation behavior of chitosan, grafted chitosan and reaction of grafted with metals were evaluated by TGA under nitrogen atmosphere. From the TGA curves shown in Fig 4, the differences between the samples can be noted. All the data for step stage, temperature range, weight loss $(\%)$, residue (\%) and Initial Degradation Temperature (IDT) are shown in the Table 1. Based on the data observed, initial degradation temperature of chitosan decreased from $310{ }^{\circ} \mathrm{C}$ to $180{ }^{\circ} \mathrm{C}$ after grafted. This indicated that the thermal stability of chitosan decreased after grafting.

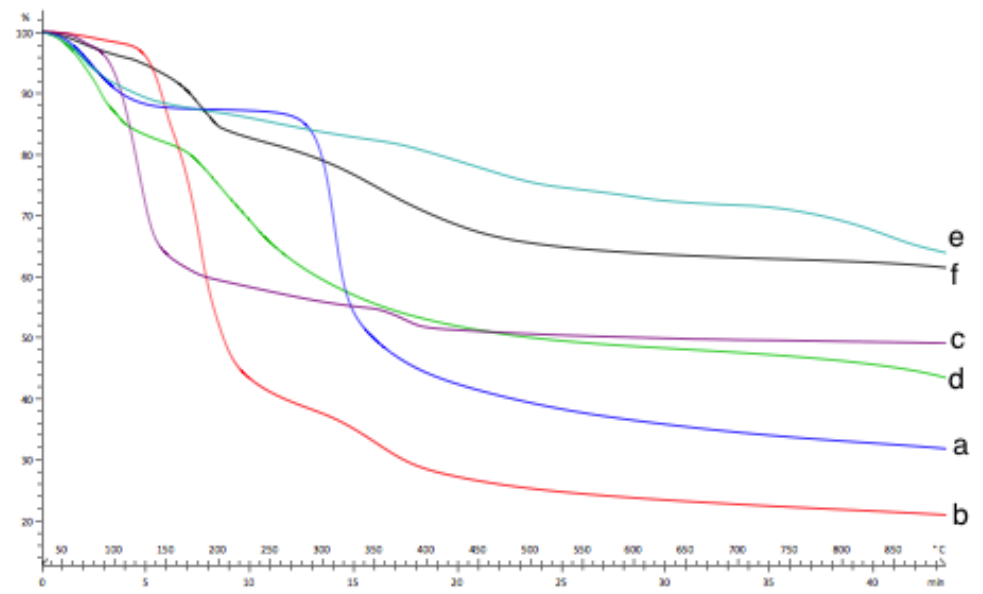

Fig. 4: TGA Curves for CS (A), CS-G-MA (B), and CS-G-MA Reacts with $\mathrm{Mg}^{2+}(\mathrm{C}), \mathrm{Na}^{+}(\mathrm{D}), \mathrm{K}^{+}(\mathrm{E}), \mathrm{Ca}^{2+}(\mathrm{F})$

For grafted chitosan react with metal, initial degradation temperature decreased. CS-g-MA react with $\mathrm{Na}^{+}$showed that the IDT was $80{ }^{\circ} \mathrm{C}$. IDT for CS-g-MA react with $\mathrm{Mg}^{2+}$ was $122{ }^{\circ} \mathrm{C}$. Then, IDT for CS-g-MA react with Ca ${ }^{2+}$ was 180 ${ }^{\circ} \mathrm{C}$. IDT for CS-g-MA react with $\mathrm{K}^{+}$was $74{ }^{\circ} \mathrm{C}$. Based on results obtained, the thermal stability of grafted chitosan was decreased after reaction with metals ion.

\subsection{Scanning electron microscope (SEM)}

The scanning electron micrograph of chitosan, grafted chitosan and after react with metals is show in Figure 5 respectively. The grafted chitosan modified the surface of chitosan significantly and making it useful for reaction with metal. It was clearly seen that the fibrous nature of chitosan was modified after grafting [15]. SEM image of chitosan was smooth and no pores or semi-pores on the surface. Because of strong interactions between chitosan and maleic acid, SEM image of grafted chitosan showed rocks like structure, which provides larger surface area for better adsorption. The structure existed of small pores and indicated for better solubility. SEM image of grafted chitosan react with $\mathrm{Na}^{+}, \mathrm{Mg}^{2+}, \mathrm{Ca}^{2+}$ and $\mathrm{K}^{+}$are modified the image of grafted chitosan and the surface morphology changed dramatically. Reaction of the grafted chitosan with $\mathrm{Na}^{+}$changed to needle like structure. For reaction with $\mathrm{K}^{+}$, the structure looked porous. Reaction with $\mathrm{Ca}^{2+}$, the surface look strong with irregular structure and reaction with $\mathrm{Mg}^{2+}$ changed the structure to not uniform. These proved that metal was reacted with the grafted chitosan and the fibrous nature of chitosan was totally modified when it was chemically modified [15].

\section{Conclusion}

Chitosan (CS) was successfully grafted with maleic acid (MA) in the presence of potassium persulfate as an initiator. The grafting yield (GY) up to $84.25 \%$ and grafting efficiency (GE) of $64.82 \%$ were achieved. The grafting of chitosan and reaction of grafted chitosan with metals were strongly confirmed by FTIR. The morphological structure by SEM revealed that the grafted chitosan has improved solubility and fractured structure. Reaction of grafted chitosan with metals $\mathrm{Na}^{+}, \mathrm{K}^{+}, \mathrm{Ca}^{2+}$ and $\mathrm{Mg}^{2+}$ also modified the structure of grafted chitosan. Crystannility and thermal stability of the chitosan decreased after grafted and also when the grafted chitosan react with metals. Reactions of grafted chitosan with metals were successfully. 
CS

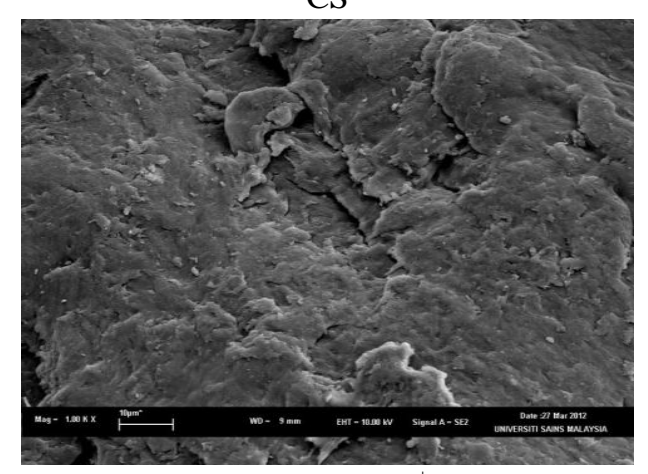

CS-g-MA-Na ${ }^{+}$

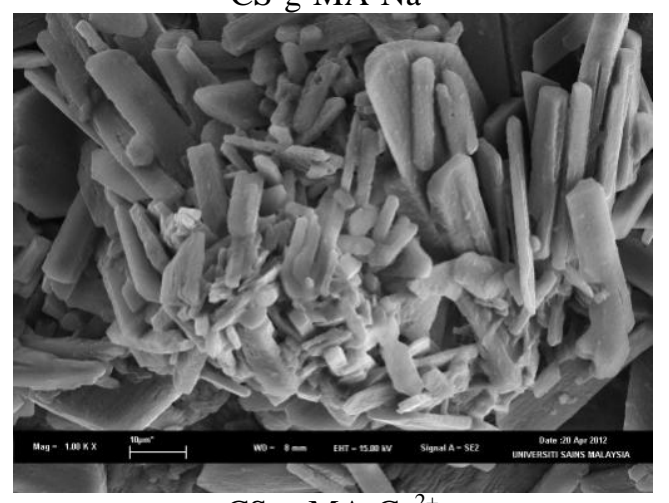

CS-g-MA-Ca ${ }^{2+}$

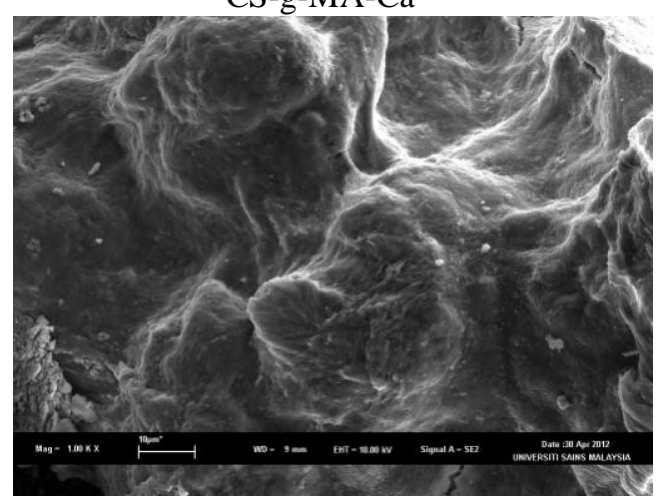

CS-g-MA

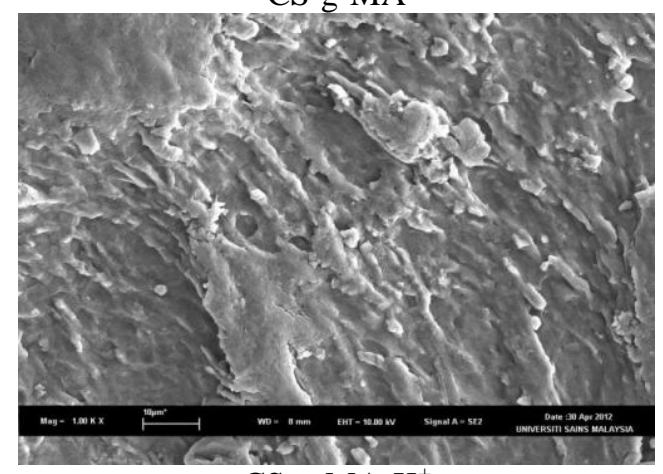

CS-g-MA-K ${ }^{+}$

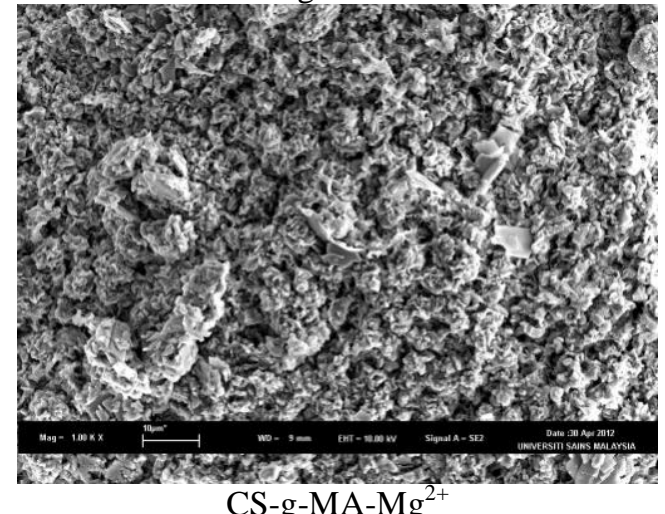

CS-g-MA-Mg

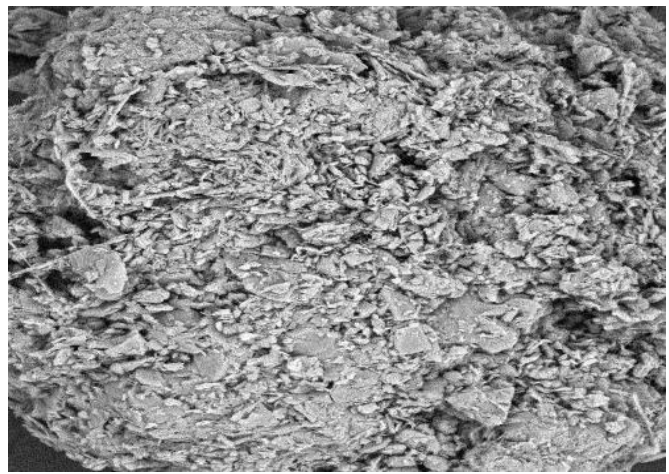

Fig. 5: Scanning Electron Micrographs of the Pure CS, CS-G-MA and CS-G-MA-Metals.

\section{References}

[1] Azevedo, H. S.; Gama, F. M.; Reis, R. L., Biomacromolecules, 4, (2003), 1703-1712. http://dx.doi.org/10.1021/bm0300397.

[2] Cascone, M. G.; Barbani, N.; Cristallini, C.; Giusti, P.; Ciardelli, G.; Lazzeri, L., Journal of Biomaterials Science, Polymer Edition, 12, (2001), 267-281. http://dx.doi.org/10.1163/156856201750180807.

[3] Chiellini, E.; Cinelli, P.; Imam, S. H.; Mao, L., Biomacromolecules, 2, (2001), 1029-1037. http://dx.doi.org/10.1021/bm010084j.

[4] Cristallini, C.; Barbani, N.; Giusti, P.; Lazzeri, L.; Cascone, M. G.; Ciardelli, G. Macromolecular Chemisty and Physics, 202, (2001), $2104-$ 2113. http://dx.doi.org/10.1002/1521-3935(20010601)202:10<2104::AID-MACP2104>3.0.CO;2-H.

[5] Cascone, M. G.; Sim, B.; Downes, S., Biomaterials, 16, (1995), 569-574. http://dx.doi.org/10.1016/0142-9612(95)91131-H.

[6] Ly, E. B.; Bras, J.; Sadocco, P.; Belgacem, M. N.; Dufresne, A.; Thielemans, W., Materials Chemistry and Physics, 120, (2010), $438-445$. http://dx.doi.org/10.1016/j.matchemphys.2009.11.032.

[7] Meshram, M. W.; Patil, V. V.; Mhaske, S. T.; Thorat, B. N., Carbohydrate Polymers, 75, (2009), 71-78. http://dx.doi.org/10.1016/j.carbpol.2008.06.012.

[8] Mishra, A.; Pal, S., Carbohydrate Polymers, 68, (2007), 95-100 http://dx.doi.org/10.1016/j.carbpol.2006.07.014

[9] Ayoub, M.M.H.; Nasr, H.E.; Darweesh, M.H.H.; Negim, S.M., J. Polymer-Plastics Technology and Engineering, 44, (2005), $305-319$.

[10] Ayoub, MMH.; Darweesh, H.H.M.; Negim, S.M., Cemento Hormigon, 919, (2007), 4-15.

[11] El-Sayed, Negim; Mahyuddin, Ramli; Saber, E. Mansour; Bahruddin, Saad; Muhammad, Idiris, J. World Applied Science, 10(4), (2010), 443450, 2010.

[12] Ruel-Gariépy, E.; Leroux, J.-C., European Journal of Pharmaceutics and Biopharmaceutics, 58, (2004), $409-426$. http://dx.doi.org/10.1016/j.ejpb.2004.03.019.

[13] Ruel-Gariépy, E.; Leclair, G.; Hildgen, P.; Gupta, A.; Leroux, J.-C., Journal of Controlled Release, 82, (2002), $373-383$. http://dx.doi.org/10.1016/S0168-3659(02)00146-3.

[14] Ta, H. T.; Dass, C. R.; Dunstan, D. E., Journal of Controlled Release, 126, (2008), 205-216. http://dx.doi.org/10.1016/j.jconrel.2007.11.018.

[15] Kumar, M. N. V. R.; Muzzarelli, R. A. A.; Muzzarelli, C.; Sashiwa, H.; Domb, A. J., Chemical Reviews, 104, 12, (2004), 6017-6084. 